\title{
A informação nas relações entre os Agentes Comunitários de Saúde e os usuários do Programa de Saúde da Família
}

\section{The information in communitary health agent and the patients' relations at Family Health Program}

Paulo Antonio de Carvalho Fortes

Prof. Associado do Departamento de Prática de Saúde Pública da Faculdade de Saúde Pública da Universidade de São Paulo

E-mail: pacfuspœusp.br

\section{Simone Ribeiro Spinetti}

Assistente Social da Secretaria Municipal da Saúde de São Paulo

E-mail: srspiळhotmail.com

\section{Resumo}

Estudo exploratório que objetivou conhecer a visão de atores sociais do Programa de Saúde da Família da cidade de São Paulo sobre a informação contida nas relações entre os Agentes Comunitários de Saúde e os usuários. Foram entrevistados: Chefias das Unidades, Médicos, Enfermeiros e Agentes Comunitários de Saúde, entre agosto e setembro de 2002. Os discursos dos gerentes e profissionais de saúde demonstram tendência de que a informação do ACS deva se ater a questões administrativas e à organização dos serviços, mediada e decidida pelos profissionais de saúde, evitando informação sobre patologias ou agravos à saúde. 0 discurso predominante dos ACS, apesar de compreenderem que não faça parte de sua função conhecer o diagnóstico dos pacientes ou informar sobre tratamentos, medicamentos e resultados de exames, denota o interesse na maior compreensão das patologias dos usuários, no sentido de auxiliá-los em suas demandas. Seu posicionamento, de acordo aos propósitos do PSF, não demonstra tentativas em se apropriar das competências dos outros elementos da equipe de saúde.

Palavras-chave: Bioética; Ética das organizações; Informação 
Abstract

This is an exploratory study to investigate the views of the various social active members in the Family Health Program of São Paulo about the information among the relation of Community Health Agents (Agentes Comunitários de Saúde). Between August and September of 2002, several healthcare professionals were interviewed, such as: The Head of Basic Healthcare Units, Physicians, Nurses and Community Health Agents. The speech of managers and professionals showed that the Agent information should be restrict to administrative and organizational matters, intervened and decided by healthcare professionals, avoiding information about pathologies or health injury. The Agent predominant speech, nevertheless the understanding that their functions is not to know the patients diagnosis or to provide information about treatments, medicines or exams results, they express interest to know more about the users pathologies in order to help them in theirs demands. Also, was showed an agreement in relation of the objectives of the Program, without been observed the endeavor of the Agent to insert in the competency of the other professionals of the Health Family Program team.

Key Words: Bioethics; Organizational Ethics; Information.

\section{Introdução}

O Programa de Saúde da Família (PSF) foi criado pelo Ministério da Saúde em 1994, e corresponde a uma estratégia de reordenação do setor saúde a partir da atenção primária, tendo suas origens conceituais fundadas na Conferência Internacional sobre Cuidados Primários, ocorrida em 1978, em Alma-Ata e na estratégia de "Saúde para todos no ano 200o", proposta pela Organização Mundial da Saúde, em 1979.

o Programa de Saúde da Família tem como uma de suas características mais marcantes a inclusão do Agente Comunitário de Saúde (ACS) na equipe de saúde. Este começou a ser incorporado ao sistema público de saúde a partir de 1991, com a criação do Programa de Agentes Comunitários de Saúde (PACS), pelo Ministério da Saúde (Brasil 2001).

O ACS possui uma situação singular, uma vez que deve obrigatoriamente residir na área de atuação da equipe e exercer a função de elo de ligação entre a equipe e a comunidade, o que faz com que viva o cotidiano da comunidade com maior intensidade do que os outros membros da equipe de saúde.

Pressupõe-se que o Agente Comunitário de Saúde, exercendo a função de elo de ligação entre a equipe e a comunidade, tendo maior proximidade com o usuário e adentrando freqüentemente no domicílio do usuário, deva estar capacitado a estabelecer relações que favoreçam o levantamento das informações sobre a saúde individual e familiar daqueles com quem se relaciona na comunidade.

Assim, tendo como marco o direito dos usuários à informação, nos propusemos a realizar um estudo de natureza exploratória, objetivando conhecer a visão (opiniões e expectativas) de diversos atores sociais envolvidos no Programa de Saúde da Família, vigente na cidade de São Paulo, sobre a informação contida nas relações entre o ACS e os usuários, entendendo que as peculiaridades deste município podem trazer diferenças de experiências anteriores com PSF realizadas em regiões rurais ou em locais com características econômicas, sociais e culturais diversas da grande metrópole. 


\section{Procedimentos Metodológicos}

Realizou-se pesquisa qualitativa, de caráter exploratório, com orientação analítico-descritiva. Pesquisa orientada pela ética descritiva, que é a investigação da conduta moral, utilizando-se de procedimentos e metodologias de cunho científico para estudar como as pessoas equacionam e agem, ou ainda como se comportam em circunstâncias particulares que trazem problemas éticos (Zoboli 2003).

Utilizou-se amostragem não probabilística, tipo acidental, não existindo definição prévia do número de pesquisados, pois se objetivava atingir o ponto de saturação que refletisse as tendências prevalentes dos grupos pesquisados, segundo as orientações de MINAYO (1994) e CONTRANDIOPOULOS et al. (1994).

Optou-se por pesquisar unidades de saúde de o2 Distritos de Saúde (Coordenadorias de Saúde a partir de 2003) que estavam iniciando a implementação do PSF. Foram escolhidos o Distrito de Santo Amaro (Unidade Básica do Jardim Niterói) e o Distrito de Saúde de Cidade Ademar (Unidade Básica do Jardim Guacuri).

Foram entrevistados: as Chefias das Unidades Básicas de Saúde ( $n=2)$, a totalidade de Médicos ( $n=6)$ e Enfermeiros $(n=3)$ participantes das Equipes de Saúde da Família e metade dos Agentes Comunitários de Saúde ( $\mathrm{n=24}$ ). As entrevistas se deram em agosto e setembro de 2002, após a capacitação inicial dos ACS.

Os Gerentes, médicos e enfermeiros foram submetidos a entrevistas semi-estruturadas, com questões abertas, sendo o roteiro inicial de entrevista:

1. Qual o papel a ser desempenhado pelos agentes comunitários de saúde?

2. Quais as informações que o agente de saúde deve fornecer aos usuários?

Os agentes comunitários de saúde foram também pesquisados mediante entrevistas semi-estruturadas, com uma questão aberta:

1. Em sua opinião quais são as informações que você deve e pode dar a um usuário?

A interpretação do material coletado seguiu os ensinamentos de GIL (1995) e BARDIN (1994), mediante a técnica de "análise de conteúdo", escolhida pela possibilidade de adequação às diversas condições (locus) de produção da palavra ocorridas na pesquisa. No item "resultados e análise" são apresentadas al- gumas expressões-chave, relacionadas às categorias obtidas.

Segundo as diretrizes e normas da Resolução CNS/ MS 196/96, a cada um dos sujeitos da pesquisa foi demandado o consentimento expresso para participar no estudo. Todos os entrevistados foram mantidos sob anonimato, sendo os resultados apresentados mediante siglas seguidas por numeração, por exemplo, Médicos: M (1,2,3, etc); Enfermeiros: E (1,2,3, etc); Gerentes de Unidades: G $(1,2)$; Agentes comunitários de saúde: ACS (1,2,3, etc). Aos dirigentes das instituições foi solicitada autorização prévia para a realização da pesquisa. A eles não foi revelado nenhum dado isoladamente e tampouco a decisão individual de cada profissional em participar ou não da pesquisa. 0 projeto de pesquisa foi submetido e aprovado pelo Comitê de Ética em Pesquisa da Faculdade de Saúde Pública em 16 de outubro de 2001. A pesquisa foi financiada e aprovada em seu relatório final pela FAPESP, processo $\mathrm{n}^{0} 2001 / 11031-7$.

\section{Resultados}

\section{Gerentes e profissionais de saúde}

Nos discursos dos gerentes das unidades fica patente a preocupação em capacitar o ACS para a relação com a comunidade:

“(...) colocar este Agente Comunitário na rua sem uma coordenação adequada, a gente avaliou que era melhor que ele ficasse na Unidade, e aí a gente começou a tá introduzindo eles nos vários setores, até para conhecer melhor então". (G1)

"Eu acho que futuramente eles vão ter muito mais coisas para desempenhar depois que eles estiverem capacitados, então esta é a experiência que nós temos hoje com um pouquinho do que eles foram treinados, na realidade ainda falta muita coisa para capacitálos". (G2)

Houve tendência marcante do discurso que defende que a informação prestada pelo ACS ao usuário deva se ater a questões administrativas e sobre a organização dos serviços:

"As informações seriam desde de toda esta rotina do serviço, ajudar a esclarecer o que está acontecendo na unidade; ele deve manter a comunidade informada da nossa proposta, (...); como o trabalho dele é 
basicamente na rua, então seria dar informação da proposta, divulgar a proposta de trabalho nossa. Com essa nova visão de saúde, dar toda essa informação em termos de funcionamento da unidade, o que a gente tem para oferecer, em que dia, que horário, os porquês também (...)”. (G2)

"São informações que eles vão dar da comunidade, em si, em termos administrativos e de funcionamento e informações outras em relação a cuidados mesmos, no dia-a-dia dessa pessoa”. (G2)

"Todas as informações referentes ao Posto, como proceder para marcar uma consulta ou para obter alguma coisa, ajudar o usuário na manutenção de um exame subsidiário que o Posto não forneça, por exemplo, um ultra-som ou uma consulta de especialista. Orientar a eles quanto à conduta médica quando, por exemplo, você dá uma determinada dose de medicação. Ensinar a pessoa a tomar aquela medicação, que às vezes a pessoa nem sabe ler direito ou não entende (...)". (M4)

Os discursos também apontam para o fato de que a informação a ser transmitida pelo agente ao usuário deva ser fortemente mediada e decidida por aquilo que os profissionais de cada equipe entendem que deva ser veiculado, evitando informações sobre as patologias:

“O profissional enfermeiro e o médico vão descobrir que na sua área o maior problema, por exemplo, é um córrego que tá atrapalhando e vem trazendo verminose para suas crianças. Então o agente comunitário vai ter que ser trabalhado com relação à verminose, com relação ao saneamento básico pra, estar desenvolvendo um papel junto com os facilitadores, para estar melhorando esta questão”. (E2)

"No meu entender, as informações que eles devem fornecer devem ser exclusivamente ações do Programa de Saúde da Família, ações gerais. Não ficar se detendo com doenças, nada disso! Apenas ações que visem informar as pessoas na tentativa de colher o maior número de dados para fornecer a toda esta equipe, para que a gente possa programar uma ação de saúde". (M1)

"Bom, como o agente de saúde não tem uma formação de saúde, eu acho que as informações que ele deve fornecer aos usuários são as informações que a gente vai treinando o agente na equipe na medida da necessidade". (M2)
Segundo as falas de gerentes e médicos pesquisados, o prontuário não deve ser aberto ao ACS, pois conteria fatos privativos, revelados somente na relação profissional-usuário. Consideram a importância da guarda e da manutenção do prontuário, pois a quebra da privacidade de informações pessoais poderá resultar em danos para o usuário durante o acompanhamento no serviço ou, até mesmo, posteriormente:

“Agora minha grande preocupação é que eu acho assim, dependendo do problema que o paciente tem, tem toda a questão do sigilo de prontuário, até que ponto a pessoa quer que outras pessoas saibam o que ela tem?". (G2)

“(...) eu acho que prontuário é uma coisa que não tem que estar na mão do Agente, não é da alçada de Agente de saúde (...)". (G2)

"Nós aqui não damos acesso de prontuário pros agentes de saúde. Eles entram na sala, puxam o prontuário e entregam na mão, mas abrir prontuário eles não estão autorizados”. (M2)

Para gerentes, médicos e enfermeiros, o fato do ACS não ser um profissional ou técnico regulamentado, submetido ao controle de órgãos reguladores profissionais, traz incertezas e preocupações quanto à observação da privacidade das informações dos usuários:

"A gente tem assim, reforçado, por que tem uma questão: o agente comunitário tem a formação diferente do auxiliar de enfermagem que tem a formação durante três anos (...) é, sei lá, (...) e técnico de enfermagem depois de mais um ano de formação, além do auxiliar, então é muito inicial a discussão". (G1)

“(...) porque eles não são da saúde, não têm mesmo que saber”. (E1)

\section{Agentes Comunitários de Saúde}

Pode-se verificar que a idéia de ser encarregado de propor medidas preventivas, além de ser um facilitador do acesso e orientador para a utilização adequada dos usuários às ações e serviços de saúde, está fortemente ancorada nas falas dos ACS. Quando questionados sobre o espectro e o grau de informações que deveriam fornecer aos usuários, os discursos mostraram:

“Informações com relação à consulta. Quando o pessoal tá precisando de uma consulta né, vem até nós para que nós possamos marcar. Nós fazemos uma triagem, daí então, estamos marcando uma consulta pra cada um deles, com dia e hora marcada. Na realidade, 
ele nos procura mais para assim (...) marcar consulta, ver resultado de exames. Então, ele nos procura e nós tentamos resolver da melhor forma possível. 0 resultado quem dá é a doutora”. (ACS 27)

"Esse é o papel do agente, porque o nosso papel é prevenir, porque não podemos curar, só prevenir". (ACS1)

"Informações sobre funcionamento do Posto, sobre a saúde, cuidados da saúde, informações preventivas, informações que ajudam a melhorar o bairro, informações sobre saúde mesmo”. (ACS 20)

Os ACS pesquisados entendiam que não era sua função conhecer o diagnóstico dos pacientes ou fornecer informações sobre tratamentos, medicamentos e resultados de exames:

"Não, porque quando a gente vai, não sai perguntando o que ele tem, porque nem ele sabe. A gente pede para a pessoa marcar uma consulta”. (ACS1)

“O agente comunitário deve informar que só o próprio médico pode passar o resultado do exame pra ele e que a gente vai estar marcando uma consulta e em breve ele vai estar sabendo o resultado. A gente não pode antecipar nada, a não ser o médico”. (ACS21)

Todavia, alguns pesquisados mostraram maior interesse em ter maior conhecimento sobre as patologias ou os agravos à saúde dos usuários com quem se relacionam, afirmando assim poder melhor ajudar os usuários em suas demandas:

"Na verdade, o Agente de Saúde, ele deveria ser treinado para isto, entendeu? Pra saber qual é o nome da doença, o que a pessoa tem, quando ela refere: olha tô com dor aqui! Daí eu penso, ai meu Deus! Aqui é o que? Você tá entendendo? Você sabia que aqui é um membro superior esquerdo (...) o Agente Comunitário deveria ser treinado, mas infelizmente não é!”. (ACS4)

"Eu acho que eu preciso saber, até pra eu saber lidar com a situação. Dependendo da doença como é, você tem um tato mais comum de todo mundo, senão ter uma sensibilidade de trazer eles pra você, a confiança, a credibilidade, pra que ele entre no tratamento, pra que ele vá em frente, se acredite que é possível e tal". (ACS3)

Tornam-se interessantes os discursos sobre a necessidade de informar ao usuário sobre outros fatores sociais que possam interagir com a saúde, ampliando o conceito de saúde-doença:

"Eu acho que toda a informação que está relaciona- da ao bem estar da comunidade, não só da saúde, mas tudo aquilo que envolve, moradia, cidadania, todas as informações que possa estar integrando o usuário dentro da comunidade que ele vive e o contexto social do país, é importante para a saúde dele (...)”. (ACS6)

\section{Considerações Finais}

A transformação do modelo assistencial e a humanização do atendimento nos serviços de saúde requerem que seja garantido o direito à informação do usuário. A informação é o elemento vital para que o usuário possa tomar decisões. Assim sendo, aqueles que atuam na saúde devem estar cônscios de sua responsabilidade individual em esclarecer os usuários sobre questões que lhes são mais afeitas para que se evitem posturas paternalistas, que em nome de levar benefícios às pessoas, impedem que elas tomem decisões autônomas. (Fortes \& Martins 200o)

Para tanto, o ACS deve estar capacitado a informar e esclarecer medidas ou procedimentos dentro do rol de suas atribuições. Consideramos que deva ser capacitado no sentido de poder utilizar o denominado padrão de informação “orientado ao paciente" ou “padrão subjetivo", válido para todos que atuam na área de saúde. Este padrão enseja que se estabeleça uma abordagem informativa apropriada a cada pessoa, uma informação personalizada, passando a contemplar as expectativas, os interesses e os valores de cada usuário, observados em sua individualidade (Fortes, 1998).

Sendo um recente elemento da equipe de saúde, as competências e responsabilidades do ACS têm sido estudadas e refletidas em diversos estudos, com preocupação em diferenciar a inserção institucional da inserção comunitária, a diferenciação de suas competências com as dos profissionais da equipe de enfermagem (Santos 2001; Silva 2001; Souza 2001).

A reflexão sobre o conteúdo e o grau de informação que ocorre nas relações entre o ACS e os usuários é de grande importância devido ao fato do Agente ser, muitas vezes, o primeiro elo de contato (durante a fase de cadastramento da clientela) e/ou aquele que mais terá contato com os usuários. Em nosso estudo, as falas dos entrevistados - gerentes, médicos e enfermeiros - mostraram fortes preocupações e dúvidas quanto ao conteúdo e aos limites das informações a serem veiculadas pelo Agente. 
Parece ter sido consensual que se deva estabelecer limites para o ACS com relação ao acesso a determinadas informações pessoais dos usuários, como as que se referem ao diagnóstico de doenças. Prevaleceu a orientação de restringir as informações a questões administrativas e organizacionais, sobre os serviços disponíveis e referências para a população que vive na área de abrangência de sua atuação.

Porém, se o ACS é considerado como um "olheiro" da equipe na captação das necessidades e detecção de casos de risco, a restrição de seus conhecimentos não pode levar a uma maior dificuldade em identificar situações de risco e orientar o encaminhamento dos usuários? O desconhecimento técnico e científico elementar das patologias e dos agravos à saúde não poderá comprometer as tarefas demandadas ao ACS em todos documentos que orientam o PSF?

Pode-se questionar se cabe estabelecer limites para o ACS com relação a determinadas informações pessoais dos usuários, como as que se referem ao diagnóstico de doenças, principalmente as que podem trazer algum grau de estigmatização e/ou discriminação negativa para os usuários, como HIV/aids e transtornos mentais.

SILVA (2001, p. 188), pesquisando os ACS do Projeto QUALIS, também já havia encontrado o receio de profissionais de saúde de que o desconhecimento tecnocientífico do ACS pudesse levá-lo a se basear em suas próprias crenças, além de sua experiência pessoal, para tentar solucionar algumas questões que lhe são colocadas pelos usuários.

No entanto, o receio manifesto pode ser minimizado, pois os discursos dos ACS das equipes pesquisadas apontam para o fato de que se posicionam de acordo com os propósitos do Programa de Saúde da Família. Não se detectou tentativas de apropriação das competências dos outros elementos da equipe de saúde, de acordo às orientações de seu processo de capacitação.

Assim, ao se incentivar a preocupação dos membros das equipes de saúde da família com as relações estabelecidas entre o ACS e os usuários, pode-se aventar que, em ocorrendo adequadas condições de exercício de suas tarefas, o ACS estará mais apto a desenvolver ações eficientes e com a qualidade requerida para a humanização dos serviços de saúde.

\section{Referências}

BARDIN, L. Análise de conteúdo. Lisboa, Edições 7o, 1994.

CONTRANDIOPOULOS, A.P.; CHAMPAGNE, F.; POTVIN, L.; DENIS, J.L.; BOYLE,P. Saber preparar uma pesquisa. São Paulo/Rio de Janeiro, HucitecABRASCO, 1994.

FORTES, P.A.C. \& MARTINS, C.L. A ética, a humanização e a saúde da família. Revista Brasileira de Enfermagem, 53 (n. esp.): 31-33, 2000.

FORTES, P.A.C. Ética e Saúde. São Paulo, Pedagógica Universitária, 1998.

GIL, A.C. Como elaborar projetos de pesquisa. São Paulo, Atlas, 1995.

MINAYO, M.C.S. $O$ desafio do conhecimento. Pesquisa qualitativa em saúde. São Paulo/ Rio de Janeiro, Hucitec/Abrasco, 1994.

SANTOS, R.M.B. Projeto Qualidade Integral em Saúde (QUALIS): relato de uma experiência (abril de 1996 a junho de 1999). Dissertação de Mestrado. São Paulo, Faculdade de Saúde Pública USP, 2001.

SILVA, J.A. da. O agente comunitário de saúde do Projeto Qualis: agente institucional ou agente comunitário? Tese de Doutorado. São Paulo, Faculdade de Saúde Pública USP, 2001.

SOUSA, M.F. Agentes comunitários de saúde: Choque de Povo. São Paulo, Hucitec, 2001.

ZOBOLI, E.L.C.P. Bioética e atenção básica: um estudo de ética descritiva com enfermeiros e médicos do Programa de Saúde da Família. Tese de Doutorado. São Paulo, Faculdade de Saúde Pública, Universidade de São Paulo, 2003.

Recebido em: 27/01/2004

Aprovado em: 06/05/2004 